\title{
9-Aryl Substituted Hydroxylated Xanthen-3-ones: Synthesis, Structure and Antioxidant Potency Evaluation
}

\author{
Elma Veljović, ${ }^{a}$ Selma Špirtović-Halilović, ${ }^{a}$ Samija Muratović, ${ }^{a}$ Lidija Valek Žulj, ${ }^{b}$ Sunčica Roca, ${ }^{c}$ \\ Snežana Trifunović, ${ }^{\mathrm{d}}$ Amar Osmanović, ${ }^{\mathrm{a}, *}$ and Davorka Završnik ${ }^{\mathrm{a}}$ \\ a Department of Pharmaceutical Chemistry, Faculty of Pharmacy, University of Sarajevo, Zmaja od Bosne 8, \\ 71000 Sarajevo, Bosnia and Herzegovina \\ ${ }^{\mathrm{b}}$ Department of Electrochemistry, Faculty of Chemical Engineering and Technology, University of Zagreb, \\ Marulićev trg 19, 10000 Zagreb, Croatia \\ ${ }^{\mathrm{c} N M R}$ Centre, Ruđer Bošković Institute, Bijenička cesta 54, 10000 Zagreb, Croatia \\ ${ }^{\mathrm{d}}$ Faculty of Chemistry, University of Belgrade, Studentski trg 16, 11000 Belgrade, Serbia
}

RECEIVED JANUARY 9, 2015; REVISED MARCH 27, 2015; ACCEPTED APRIL 7, 2015

\begin{abstract}
Oxidative stress is directly related to several diseases and symptoms, where antioxidant compounds, such as xanthenes, may become important in prevention and/or treatmant. Ten biologically active 9-aryl substituted 2,6,7-trihydroxyxanthen-3-one derivatives were synthesized using reliable one-pot synthesis and their structures were confirmed by IR, ${ }^{1} \mathrm{H}$ and ${ }^{13} \mathrm{C}$ NMR spectroscopy and mass spectrometry. Some of the synthesized compounds were scanned for their antioxidant potency using electrochemical method cyclic voltammetry of immobilized microparticles. Substitution of hydrogen at the phenyl ring of 2,6,7-trihydroxy-9-phenylxanthen-3-one with an electron-donating group affected the reducing power of the compounds by lowering the biological oxidation potential. These results signify the importance of xanthen-3-one derivatives as antioxidant agents and their further biological evaluation.
\end{abstract}

Keywords: xanthen-3-one derivatives, antioxidant potency, cyclic voltammetry

\section{INTRODUCTION}

Xanthenes and benzoxanthenes constitute as important class of biologically active heterocycles due to their broad spectrum of pharmacological activities, such as antibacterial, ${ }^{1}$ antiviral, ${ }^{2}$ antiprotosoal, ${ }^{3}$ antitumor, ${ }^{4,5}$ anti-inflammatory ${ }^{6}$ and cardiovascular protective effects. ${ }^{7}$ Additionally, they can be employed as dyes, ${ }^{8} \mathrm{pH}$ sensitive fluorescent materials for visualisation of biomolecular assemblies ${ }^{9}$ and in laser technologies. ${ }^{10} \mathrm{Be}-$ cause of all these beneficial properties their synthesis has drawn great attention in the field of medicinal and pharmaceutical chemistry.

There are several diseases and symptoms directly related to oxidative stress, such as: atherosclerosis, Alzheimer, cancer, aging process and central nervous degeneration. ${ }^{11}$ Antioxidant compounds may become important in preventing and/or treating these diseases.

It has been proven by numerous studies that xanthenes possess significant antioxidant activity and different methods for determining this potency have been described and employed. ${ }^{11-15}$

One of the widely used methods, available and relatively inexpensive is spectrophotometric assay with 2,2-diphenyl-1-picrylhydrazyl (DPPH) reagent. ${ }^{16}$ While good and adequate for many compounds and samples, ${ }^{12,16}$ it is not suitable for coloured, fluorescent or poorly soluble compounds as happens to be common for some xanthene derivatives.

Electrochemical techniques offer a rapid and simple alternative method for the analysis of bioactive compounds with antioxidant properties in crude samples. Cyclic voltammetry, a type of potentiodynamic electrochemical measurement, has numerous advantages over the other mentioned methods; it is rapid, affordable and sensitive enough for determination of antioxidative properties of samples. ${ }^{17}$ Cyclic voltammetry scans may be used to determine the ability of selected compounds to donate an electron around the oxidation potential of the anodic peak. High correlations with standard methods, according to obtained results, recommend cyclic voltammetry as good alternative to conventional spec-

\footnotetext{
* Author to whom correspondence should be addressed. (E-mail: amar.ffsa@gmail.com)
} 
trophotometric assays. ${ }^{16,17}$ So far, it has been described as method used for evaluation of antioxidant potency of complex samples such as: fruit juices, wines, teas, etc. ${ }^{16-18}$ However, there are only few studies using voltametric methods for antioxidant evaluation of synthesized compounds. ${ }^{19}$ Voltammetry of immobilized microparticles conducted on carbon paste electrode enables electrochemical characterization of poorly soluble compounds. Scholz and co-workers introduced the method, voltammetry of immobilized microparticles, to analytical practice in year 1998 as a new tool in electrochemical analysis. ${ }^{20} \mathrm{~A}$ method has been applied for identification and quantification of natural products, and estimation of antioxidant properties of tea leaves, fruit and vegetables. ${ }^{21-23}$ An application of method in the investigation of electrochemical and surface properties of solid materials grew over the years, validating the method as useful analytical tool. Of significant importance is the fact that the solid-state processes in microparticles are phase-characteristic, which enables the electrochemical characterization of the respective solid materials, and the acquisition of valuable information about their redox behaviour.

In the present paper, ten 9-aryl substituted 2,6,7trihydroxyxanthen-3-one derivatives were prepared using reliable one-pot method of synthesis ${ }^{24,25}$ followed by structure elucidation. Due to their interesting polyphenolic structure and present functional groups, voltammetry of immobilized microparticles was used to characterize the electrochemical behaviour. Microparticles of synthesized compounds were immobilized at carbon paste electrode as specifically suitable method employed because of their poor solubility.

\section{EXPERIMENTAL}

\section{Instrumentation}

Melting points of the compounds were determined with BÜCHI Melting Point B-545 and are presented uncorrected. Infrared (IR) spectra of synthesized compounds were recorded by Shimadzu IR Prestige 21 ID using $\mathrm{KBr}$ pellets. The ${ }^{1} \mathrm{H}$ and ${ }^{13} \mathrm{C}$ nuclear magnetic resonance (NMR) spectra were recorded at 600 and 150 $\mathrm{MHz}$, respectively, in deuterated dimethyl sulfoxide (DMSO- $d_{6}$ ) at $25{ }^{\circ} \mathrm{C}$ using NMR spectrometer Bruker AV600, with tetramethylsilane (TMS) as internal reference. Chemical shifts $(\delta)$ are reported in ppm and coupling constants $(J)$ in Hz. Electrospray ionization mass spectrometry (ESI-MS) measurements operating in a positive and negative ion modes were performed on a high performance liquid chromatography-mass spectrometry (HPLC-MS) triple quadrupole 6420 instrument equipped with an autosampler (Agilent Technologies, Palo Alto, CA, USA). The desolvation gas temperature was $300{ }^{\circ} \mathrm{C}$ with flow rate of $6.0 \mathrm{~L}$ $\min ^{-1}$. The fragmentor voltage was $135 \mathrm{~V}$ and capillary voltage was $4.0 \mathrm{kV}$. Mobile phase was $0.1 \%$ formic acid in $50 \%$ methanol and a flow rate of mobile phase was $0.2 \mathrm{~mL} \mathrm{~min}^{-1}$. Mass spectra as total ion current spectra were recorded in $\mathrm{m} / \mathrm{z}$ segment of 10-2250. All data acquisition and processing was performed using Agilent MassHunter software. Cyclic voltamograms were recorded at scan rate $100 \mathrm{mV} \mathrm{s}^{-1}$ in the potential range $-0.8 \mathrm{~V}_{\mathrm{SCE}}$ to $1.2 \mathrm{~V}_{\mathrm{SCE}}$ (saturated calomel electrode), using a Princeton Applied Research EG\&G potentiostat (Model 273).

\section{General Procedure for Synthesis of Xanthen-3-one Derivatives}

Derivatives of xanthen-3-ones have been prepared according to known procedure which includes two-fold Friedel-Crafts alkylation of 1,2,4-triacetoxybenzene, reflux in ethanol $(\mathrm{EtOH})$ and sulphuric acid with addition of different benzaldehydes. ${ }^{24,25}$ Potassium peroxodisulphate was used as an oxidizing agent. All chemicals used for synthesis of xanthen-3-one derivatives were purchased from Sigma-Aldrich, Germany.

A round-bottom flask equipped with a condenser and mechanical stirrer was filled with 1,2,4triacetoxybenzene $(5 \mathrm{~g}, 20 \mathrm{mmol})$ and $50 \% \mathrm{EtOH}(75$ $\mathrm{mL})$. Concentrated sulphuric acid $(3 \mathrm{~mL})$ was added and the white suspension was heated to reflux, resulting in a clear, honey-coloured solution. Different benzaldehydes (10 mmol) were then added to this mixture dropwise, within 2 minute period. The stirred mixture was kept at reflux for another 60 minutes. Subsequently, potassium peroxodisulphate $(2.70 \mathrm{~g}, 10 \mathrm{mmol})$ was added in small portions at $80{ }^{\circ} \mathrm{C}$ within a period of 50 minutes. The contents were brought to reflux for another 20 minutes and then poured onto ice water. Obtained red crystals were washed with water and dried in vacuum at $60{ }^{\circ} \mathrm{C}$.

Spectral data and results of elemental analysis for compounds $1,2,4,5,6,9$ and 10 are already reported. ${ }^{24,25}$

Spectral data for three new xanthen-3-one derivatives (compounds 3, 7 and 8), synthesized according to the same procedure, are shown below.

9-(2-Fluorophenyl)-2, 6, 7-trihydroxyxanthen-3-one (3) Red crude material; yield $75 \%$; m.p. $180.2{ }^{\circ} \mathrm{C}$; IR (KBr) $v_{\max } / \mathrm{cm}^{-1}: 740-770$ (ortho-substituted benzene), $1000(\mathrm{C}-\mathrm{F}), 1200$ (phenol OH), 1600 (aromatic ring), $1680(\mathrm{C}=\mathrm{O}), 2400-3500$ (phenol $\mathrm{OH}) ;{ }^{1} \mathrm{H}$ NMR (600 MHz, DMSO- $\left.d_{6}\right) \delta /$ ppm: 6.35 (s, 2H, H-1 and H-8), 6.76 (s, 2H, H-4 and H-5), 7.51 (m, 1H, H-5'), 7.52 (m, 1H, H-6'), 7.56 (m, 1H, H-3'), 7.72 (m, 1H, H-4'), 9.55 (br s, OH); ${ }^{13} \mathrm{C}$ NMR (150 MHz, DMSO- $\left.d_{6}\right) \delta /$ ppm: 102.5 (C-4 and C-5), 106.1 (C-1 and C-8), 115.9 (C-11 and C-14), $116.2\left(\mathrm{~d}, J_{\mathrm{CF}}=21.5 \mathrm{~Hz}, \mathrm{C}-3^{\prime}\right), 121.0\left(\mathrm{~d}, J_{\mathrm{CF}}\right.$ 
$\left.=16.7 \mathrm{~Hz}, \mathrm{C}-1^{\prime}\right), 125.1\left(\mathrm{~d}, J_{\mathrm{CF}}=2.8 \mathrm{~Hz}, \mathrm{C}-6^{\prime}\right), 131.5(\mathrm{~d}$, $\left.J_{\mathrm{CF}}=2.4 \mathrm{~Hz}, \mathrm{C}-5^{\prime}\right), 131.9\left(\mathrm{~d}, J_{\mathrm{CF}}=7.6 \mathrm{~Hz}, \mathrm{C}-4\right.$ '), 139.4 (C-9), 148.3 (C-2 and C-7), 152.3 (C-3 and C-6), 158.8 $\left(\mathrm{d}, J_{\mathrm{CF}}=246.2 \mathrm{~Hz}, \mathrm{C}-2^{\prime}\right)$, signals of atoms C-12 and C13 were not detected; ESI-MS: $m / z 339.2[\mathrm{M}+\mathrm{H}]^{+}$.

9-(3-Chlorophenyl)-2,6,7-trihydroxyxanthen-3-one (7) Red crude material; yield $82 \%$; m.p. $176.5^{\circ} \mathrm{C}$; IR $(\mathrm{KBr})$ $v_{\max } / \mathrm{cm}^{-1}$ : 735-770 (meta-substituted benzene), 750$800(\mathrm{C}-\mathrm{Cl}), 1056(\mathrm{C}-\mathrm{O}), 1500$ (aromatic ring), 1550-1600 $(\mathrm{C}=\mathrm{C}), \quad 1680-1750 \quad(\mathrm{C}=\mathrm{O}), \quad 2700-3200$ (phenol OH); ${ }^{1} \mathrm{H}$ NMR (600 MHz, DMSO- $\left.d_{6}\right) \delta /$ ppm: 6.47 (s, 2H, H-1 and H-8), 6.89 (s, 2H, H-4 and H-5), $7.45\left(\mathrm{dt}, 1 \mathrm{H}, J=6.9\right.$ and $\left.1.7 \mathrm{~Hz}, \mathrm{H}-6{ }^{\prime}\right), 7.61(\mathrm{t}, 1 \mathrm{H}, J$ 1.9, H-2'), 7.72 (m, 2H, H-4' and H-5'), 9.20 (br s, OH); ${ }^{13} \mathrm{C}$ NMR (150 MHz, DMSO- $\left.d_{6}\right) \delta / \mathrm{ppm}: 102.4$ (C-4 and C-5), 107.0 (C-1 and C-8), 115.5 (C-11 and C-14), 128.0 (C-6'), 128.9 (C-2'), 129.3 (C-4'), 130.8 (C-5'), 133.6 (C-1'), 135.7 (C-3'), 147.0 (C-9), 147.8 (C-2 and C-7), 152.4 (C-3 and C-6), 163.8 (C-12 and C-13); ESIMS: $m / z 355.2[\mathrm{M}+\mathrm{H}]^{+}$.

9-(2-Hydroxy-5-nitrophenyl)-2, 6,7-trihydroxyxanthen3-one (8)

Dark red crystals, yield $63 \%$; m.p. $272.1{ }^{\circ} \mathrm{C}$; IR $(\mathrm{KBr})$ $v_{\max } / \mathrm{cm}^{-1}: 860$ (trisubstituted benzene), 1200 (aromatic ring), $1247(\mathrm{C}-\mathrm{O}), 1360(\mathrm{C}-\mathrm{N}), 1550\left(\mathrm{NO}_{2}\right), 1660$ $(\mathrm{C}=\mathrm{O}), 2400-3300$ (phenol $\mathrm{OH}) ;{ }^{1} \mathrm{H}$ NMR (600 MHz, DMSO- $\left.d_{6}\right) \delta /$ ppm: 6.53 (s, 2H, H-1 and H-8), 6.98 (s, 2H, H-4 and H-5), 7.30 (d, 1H, J=9.2 Hz, H-3'), 8.21 (d, $1 \mathrm{H}, J=2.9 \mathrm{~Hz}, \mathrm{H}-6$ '), 8.40 (dd, $1 \mathrm{H}, J=9.2$ and 2.9 $\mathrm{Hz}, \mathrm{H}-4$ '), 11.53 (br s, OH); ${ }^{13} \mathrm{C}$ NMR (150 MHz, DMSO- $\left.d_{6}\right) \delta / \mathrm{ppm}: 102.3$ (C-4 and C-5), 107.1 (C-1 and C-8), 116.1 (C-11 and C-14), 116.7 (C-3'), 120.7 (C-1'), 126.8 (C-6'), 127.1 (C-4'), 139.7 (C-5'), 145.6 (C-9), 147.7 (C-2 and C-7), 152.5 (C-3 and C-6), 160.9 (C-2'), 163.4 (C-12 and C-13); ESI-MS: $m / z 382.2[\mathrm{M}+\mathrm{H}]^{+}$.

\section{Antioxidant Potency}

Antioxidant potency of synthesized compounds was tested by the electrochemical method of voltammetry of immobilized microparticles. ${ }^{26-28}$ The microparticles of compounds were immobilized at the carbon paste electrode by pressing the electrode at the glass surface containing approximately $1 \mathrm{mg}$ of compound. Measurements were performed in the $0.1 \mathrm{M}$ phosphate buffer (pH 7.4) using three electrode system. Three electrode system contained carbon paste electrode with immobilized microparticles of the compound as working electrode, platinum $(\mathrm{Pt})$ foil as counter electrode and saturated calomel electrode (SCE) as reference electrode. Prior to each measurement electrode surface was re- newed and the new compound sample was immobilized. The background signal (a cyclic voltamogram recorded with no compound immobilized) has been measured before each measurement and subtracted from the measurement with immobilized compound. Measurements were repeated for minimum three times.

\section{RESULTS AND DISCUSSION}

Ten xanthen-3-one derivatives (1-10) were prepared from 1,2,4-triacetoxybenzene and different aromatic aldehydes under acidic alcoholic conditions. After a two-fold Friedel-Crafts alkylation intermediate A was obtained. For accomplishing the transformation a single trihydroxy benzene moiety of $\mathbf{A}$ has to be oxidized by using pottasium peroxodisulphate to the corresponding $p$-benzoquinone. In order to avoid decomposition of pottasium peroxdisulphate, the reaction of oxidation occurs at $80^{\circ} \mathrm{C}$. Benzoquinone intermedier (B) subsequently undergoes a cyclocondensation reaction to the xanthenone fragment. To remove pottasium peroxodisulphate after completed oxidation, refluxed suspension was poured onto ice water and filtered. The residue was dried under vacuum at $60{ }^{\circ} \mathrm{C}$. Synthetic pathway and structures of the prepared compounds are given in Scheme 1 (adapted from references 24 and 25).

\section{Structural Characterisation of Xanthen-3-one Derivatives}

The IR spectra of three new synthesized compounds showed absorption at $2400-3600 \mathrm{~cm}^{-1}$ indicating phenyl $\mathrm{OH}$ groups. Xanthen-3-one derivative with chlorine in meta position at aryl substituent (7) showed bands at $770-780 \mathrm{~cm}^{-1}$ due to stretching vibrations of $\mathrm{C}-\mathrm{Cl}$, while compound with fluorine substituted aryl substituent (3) showed bands at $1400-1000 \mathrm{~cm}^{-1}$ due to stretching vibrations of $\mathrm{C}-\mathrm{F}$. Bands at $1550 \mathrm{~cm}^{-1}$ were visible on spectra of derivative with nitro group (8) due to stretching vibrations of $\mathrm{C}-\mathrm{NO}_{2}$. The IR spectra of new synthesized compounds showed absorption frequencies around $1660 \mathrm{~cm}^{-1}$ and $1200 \mathrm{~cm}^{-1}$ due to stretching vibrations of $\mathrm{C}=\mathrm{O}$ and phenyl groups, respectively.

The assignments of all the protons and carbons were based on the analysis of the ${ }^{1} \mathrm{H}-{ }^{1} \mathrm{H}$ correlation spectroscopy (COSY), ${ }^{1} \mathrm{H}^{-13} \mathrm{C}$ heteronuclear multiple quantum correlation (HMQC) and ${ }^{1} \mathrm{H}-{ }^{13} \mathrm{C}$ heteronuclear multiple bond correlation (HMBC) spectra. The HMBC spectra of all three compounds gave clear connectivities between $\mathrm{H}$ 5' and C-1' and between H-2', H-6', H-1, H-8 and C-9 (Figure 1). Correlations were also observed between $\mathrm{H}-1$, $\mathrm{H}-4$ and C-2, C-3 and between H-5 and C-11. 
2<smiles>[R]c1cccc(C=O)c1</smiles><smiles>[R]c1ccc(C(c2cc(O)c(O)cc2O)c2cc(O)c(O)cc2O)cc1</smiles><smiles>CCC(C1=CC(=O)C(O)=CC1=O)c1cc(O)c(O)cc1O</smiles>

A<smiles>O=CO</smiles>

$\mathrm{R}$

1: 4'-methoxy

2: 2'-chloro

6: 2'-methoxy

3: 2'-fluoro

7: 3'-chloro

4: 4'-chloro

8: 2'-hydroxy-5'-nitro

5: 4'-fluoro

9: no substituent

10: 4'-nitro

Scheme 1.

Novel compounds showed on ${ }^{1} \mathrm{H}$ NMR spectra two singlet signals between 6.35 and $6.98 \mathrm{ppm}$ that correspond to 4 protons from xanthen-3-one ring. Compound 3 with ortho substituted phenyl ring by fluorine on ${ }^{1} \mathrm{H}$ NMR revealed 4 multiplet signals at 7.72, 7.56, 7.52 and $7.51 \mathrm{ppm}$. Compound 7 with meta substituted phenyl ring on ${ }^{1} \mathrm{H}$ NMR spectrum revealed one multiplet at $7.72 \mathrm{ppm}$, one doublet of triplets at 7.61 $\mathrm{ppm}$ and one triplet signal at $7.45 \mathrm{ppm}$. Compound 8 with trisubstituted phenyl ring at positions 2 and 5 on ${ }^{1} \mathrm{H}$ NMR showed two doublet signals at 8.21 and $7.30 \mathrm{ppm}$ and one doublet of doublets at $8.40 \mathrm{ppm}$. Characteristic

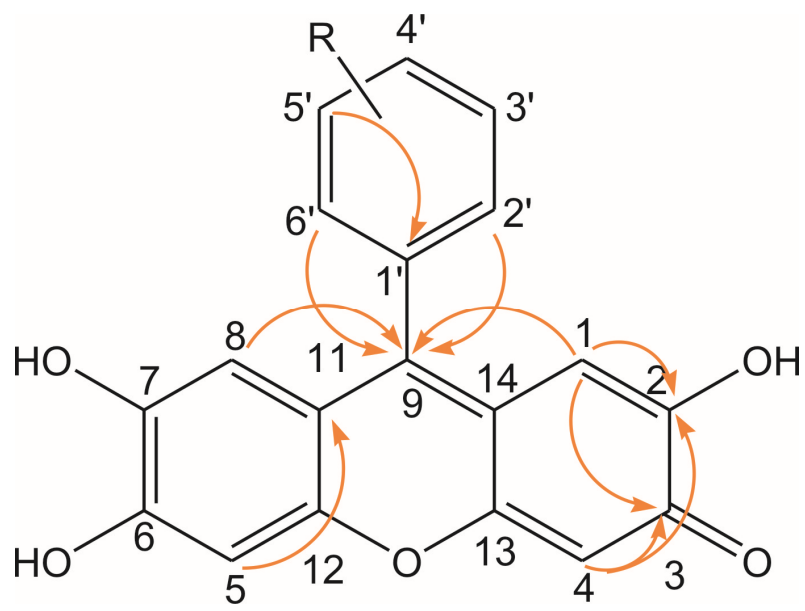

Figure 1. Key HMBC correlations of compounds 3, 7 and $\mathbf{8}$. signals of xanthen-3-one ring as well as all signals of characteristic substituent were found in ${ }^{13} \mathrm{C}$ NMR spectra of all synthesized compounds.

\section{Antioxidant Potency}

Experimental investigations as well as clinical and epidemiological findings have provided evidence supporting the role of reactive oxygen metabolites or free radicals in etiology of several diseases and symptoms. ${ }^{29}$ For example, disruption of balance between the free radicals and the antioxidants may lead to cellular damage and trigger carcinogenesis. ${ }^{30}$ Synthesis of new efficient antioxidant compounds has become urgent need for the prevention and treatment of mentioned pathological changes.

Antioxidant potency of synthesized compounds was studied by electrochemical method of cyclic voltammetry applied on the immobilized microparticles of studied compounds. This method enables characterization of antioxidant activity of compounds as well as compound mixtures in selective electro-oxidation process controlled by the potential. ${ }^{31,32}$ The applicability of electrochemistry seems logical since the antioxidant power of a compound in a reaction with a free radical is directly correlated to its ability to act as a reducing agent at an electrode. ${ }^{33-35}$ The antioxidant potency of a compound determined by the electrochemical method of cyclic voltammetry enables characterization of the ob- 


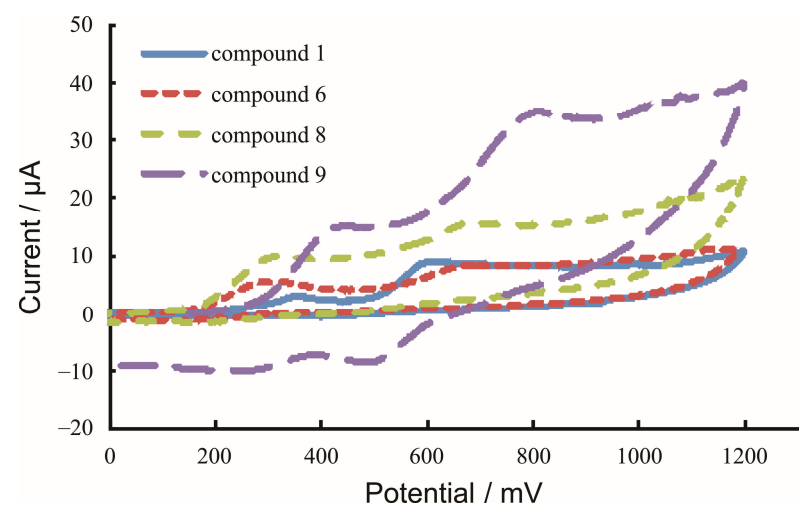

Figure 2. Cyclic voltamograms of xanthen-3-one derivatives $(\mathbf{1}, \mathbf{6}, \mathbf{8}$ and 9) microparticles immobilised at the carbon paste electrode.

tained voltammetric spectra through the anodic peak potentials. These potentials reflect the biological oxidation potential of the compound i.e. the tendency of the compound to oxidize in order to neutralize free radicals. The spectra may be analyzed also through the intensity of the peak, i.e. current density that reflects the concentration of the compound available for the reaction according to the Randles-Sevcik equation, quantitative analysis. However, due to the limitations of the immobilization methodology, quantitative analysis of the results was not possible to conduct. However, the intensity of the peaks may be considered as a compound characteristic, availability for the oxidation reaction, in a semiquantitative manner, so it will be commented in the further discussion.

Cyclic voltamograms of the chosen compounds tested for the antioxidant potency are presented in Figures 2 and 3.

According to the electrochemical behaviour, compounds separated into 2 groups, as presented in separate figures. Compound 9 showed two well pronounced anodic and two cathodic peaks of significant intensity. The presence of intensive cathodic peak is an indication of the reversibility of the electrochemical processes present at the electrode surface. Compound has no substituents at the phenyl ring, hence it was taken as basic compound for the comparison of the antioxidant behaviour of the compounds with substituents at the phenyl ring. Characteristic reversible behaviour with similar peak potential (approximately $440 \mathrm{mV}$ in the neutral media) has been obtained for the typical natural compounds with polyphenolic structure, and has been ascribed to the oxidation of the ortho-diphenol group at the phenol ring forming ortho-quinone group. However, the explanation of the second reversible peak of higher intensity occurring at the higher potential (approximately $800 \mathrm{mV}$ ) could not be so easily deduced. A possibility is that at higher potentials less oxidizable $\mathrm{OH}$ groups

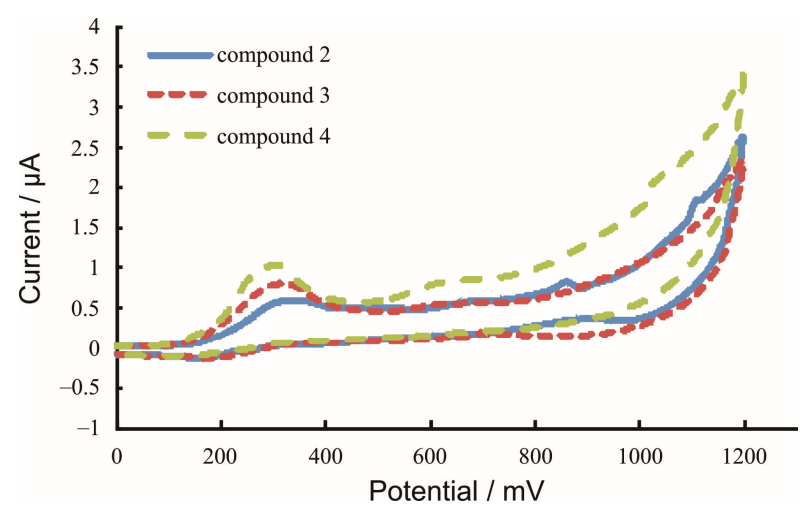

Figure 3. Cyclic voltamograms of xanthen-3-one derivatives (2, 3 and 4) microparticles immobilised at the carbon paste electrode.

may become oxidized. The peak could be ascribed to the electrochemical reaction of the mono-hydroxyl group at the position 2 of the compound 9 . However, the electrochemical oxidation of the mono-hydroxyl group at the polyphenolic compounds usually occurs in the irreversible manner. Other possible explanation may be the occurrence of the chemical reactions subsequent to the one-electron or two-electron oxidation that may introduce new oxidizable species into the solution near the electrode or at the electrode surface. If newly formed species oxidize at potentials significantly different than that of the original phenolic compound itself, multiple-peak voltammetric curve may be obtained. Due to the partial solubility of studied compounds, electrochemical reaction may proceed through solid-state reaction or through the transport of reactants from solution to the electrode surface. The solubility of the compound may hence affect significantly the intensity of the current peaks of the cyclic voltamograms. Simultaneous processes occur, electron transfer across the microparticle/electrode interface and molecule dissolution at the microparticle/solution interface.

Compound 1 showed cyclic voltamogram with anodic peaks similar to compound $\mathbf{9}$ but lower intensity. No cathodic peak appeared pointing to the irreversibility of the processes at the electrode surface. The peak potentials were slightly shifted towards lower potentials. Change of the electrochemical behaviour of the compound $\mathbf{1}$ may be presumed to be the influenced by the methoxy group introduced in the molecular structure. Compounds $\mathbf{6}$ and $\mathbf{8}$ showed anodic peaks at the significantly lower potentials with none of the cathodic peaks obtained. Lower potentials of the first anodic peak, approximately $100 \mathrm{mV}$, may be considered as indicator of higher reductive power of the compounds. Compounds 2, 3 and $\mathbf{4}$ showed very similar behaviour with anodic currents of lower intensity, second anodic peak with very weak current and none of the cathodic peaks. 
Table 1. Electrochemical parameters determined from cyclic voltamograms measured for synthesized xanthene derivatives by voltammetry of immobilized microparticles

\begin{tabular}{|c|c|c|c|c|c|c|c|c|c|c|c|}
\hline \multirow{2}{*}{ Compound } & \multicolumn{2}{|c|}{$E_{\mathrm{p}, \mathrm{a}} / \mathrm{mV}$} & \multicolumn{2}{|c|}{$I_{\mathrm{p}, \mathrm{a}} / \mu \mathrm{A}$} & \multicolumn{2}{|c|}{$E_{\mathrm{p}, \mathrm{c}} / \mathrm{mV}$} & \multicolumn{2}{|c|}{$I_{\mathrm{p}, \mathrm{c}} / \mu \mathrm{A}$} & \multirow{2}{*}{$\frac{E_{\mathrm{p} / 2}}{\mathrm{mV}}$} & \multirow{2}{*}{$\frac{E_{\mathrm{p}, a 1}-E_{\mathrm{p} / 2}}{\mathrm{mV}}$} & \multirow{2}{*}{$\frac{\left(E_{\mathrm{p}, a 1}+E_{\mathrm{p} / 2}\right) / 2}{\mathrm{mV}}$} \\
\hline & 1. peak & 2. peak & 1. peak & 2. peak & 1. peak & 2. peak & 1. peak & 2. peak & & & \\
\hline 1 & 346 & 592 & 3.1 & 8.6 & - & - & - & - & 288 & 58 & 317 \\
\hline 2 & 338 & 673 & 0.57 & 0.58 & - & - & - & - & 240 & 98 & 289 \\
\hline 3 & 318 & 644 & 0.79 & 0.55 & - & - & - & - & 219 & 99 & 269 \\
\hline 4 & 307 & 618 & 1.0 & 0.80 & - & - & - & - & 216 & 91 & 262 \\
\hline 6 & 307 & 678 & 4.1 & 5.5 & - & - & - & - & 221 & 86 & 264 \\
\hline 8 & 316 & 684 & 9.6 & 15.5 & - & - & - & - & 232 & 84 & 274 \\
\hline 9 & 434 & 802 & 15.0 & 35.0 & 490 & 246 & -8.6 & -10.2 & 348 & 86 & 391 \\
\hline
\end{tabular}

These three compounds have hydrogen atom substituted by the halogen elements that may affect the electrochemical behaviour of the compounds.

Electrochemical parameters (potentials and currents of the anodic and cathodic peaks $\left.\left(E_{\mathrm{p}}, I_{\mathrm{p}}\right)\right)$ determined from the cyclic voltamograms are presented in Table 1.

Other electrochemical parameters were determined for the first anodic peak, half-peak potential $\left(E_{\mathrm{p} / 2}\right.$, (the potential at which the current reaches half its maximum)), difference between the anodic peak potential and the half-peak potential $\left(E_{\mathrm{p}, \mathrm{a} 1}-E_{\mathrm{p} / 2}-\right.$ measure of the peak broadness) and the potential midway between $E_{\mathrm{p}, \mathrm{a} 1}$ and $E_{\mathrm{p} / 2}\left(\left(E_{\mathrm{p}, \mathrm{a} 1}+E_{\mathrm{p} / 2}\right) / 2\right){ }^{36}$ The value of $\left(E_{\mathrm{p}, \mathrm{a} 1}+E_{\mathrm{p} / 2}\right) / 2$, may be used to approximate the formal potential $\left(E^{0}\right)$ for the compounds that do not exhibit cathodic peak in the reverse scan. $E^{01}$ is the formal potential, equivalent to the potential at which $c(\mathrm{RED})=c(\mathrm{OX})$, and is used as a measure of the reducing power of compounds with antioxidant properties. The formal redox potential, $E^{0}$, attributed to ortho-dihydroxyphenol group oxidation reaction, was moved toward slightly lower potentials for the compounds containing substituted group at the phenyl ring compared to the non-substituted compound 9. It may be presumed that substitution of the hydrogen atom by the electron-donating group affected the electrooxidation reaction of the molecules. The $\left(E_{\mathrm{p}, \mathrm{a}}-E_{\mathrm{p} / 2}\right)$ value for compound 1 was $58 \mathrm{mV}$ while for the other compounds significantly higher values were obtained (between 84 and $99 \mathrm{mV}$ ) pointing to the broadness of the anodic peak. Broadness of the peak may be affected by the difference in the availability of the compounds for the electrochemical reaction, induced by the solidstate or solution provided reactants.

\section{CONCLUSION}

Ten 9-aryl substituted 2,6,7-trihydroxyxanthen-3-one derivatives have been synthesized by reliable one-pot synthetic procedure. Structures of novel compounds have been elucidated and confirmed by experimental IR, ${ }^{1} \mathrm{H},{ }^{13} \mathrm{C}$ and mass spectra measurements. The assign- ments of all the protons and carbons were based on the analysis of the ${ }^{1} \mathrm{H}-{ }^{1} \mathrm{H}$ COSY, ${ }^{1} \mathrm{H}_{-}{ }^{13} \mathrm{C}$ HMQC and ${ }^{1} \mathrm{H}-{ }^{13} \mathrm{C}$ HMBC spectra. The HMBC spectra of all three compounds gave clear connectivities between $\mathrm{H}-5$ ' and $\mathrm{C}-1$ ' and between H-2', H-6', H-1, H-8 and C-9. Correlations were also observed between $\mathrm{H}-1, \mathrm{H}-4$ and $\mathrm{C}-2, \mathrm{C}-3$ and between $\mathrm{H}-5$ and $\mathrm{C}-11$.

The antioxidant potency of chosen synthesized compounds was studied by electrochemical methods of cyclic voltammetry on immobilized microparticles. The compounds were immobilized in solid state to the carbon paste electrode and subjected to electrochemical processes. From the cyclic voltamograms the electrochemical parameters were obtained and the reducing power of the compounds was characterised. It was deduced that the substitution of hydrogen at the phenyl ring with an electron-donating group affected the reducing power of the compounds by lowering the biological oxidation potential. Additional in vivo antioxidant assays are needed to confirm the potential use of these derivatives in disease prevention and/or treatment.

Since it has been proven that antioxidant potency may correlate with antitumor activity, synthesized xanthene-3-one derivatives with good antioxidative potential will be further biologically evaluated as potential antiproliferative agents.

Acknowledgements. The author, E. Veljović, is grateful to Ivanka Jerić, PhD, Divison of Organic Chemistry and Biochemistry, Ruđer Bošković Institute, Zagreb, Croatia, for providing necessary facilities to carry out the mass spectrometry measurements.

\section{REFERENCES}

1. H. Marona, H. Szkaradek, E. Karczewska, D. Trojanowska, A. Budak, P. Bober, W. Przepiórka, M. Cegla, and E. Szneler, Arch. Pharm. 342 (2009) 9.

2. K. R. M. Naidu, B. S. Krishna, M. A. Kumar, P. Arulselvan, S. I. Khalivulla, and O. Lasekan, Molecules 17 (2012) 7543.

3. A. Pontius, A. Krick, S. Kehraus, R. Brun, and G. M. König, J. Nat. Prod. 71 (2008) 1579.

4. S. Gobbi, A. Rampa, A. Bisi, F. Belluti, P. Valenti, A. Caputo, A. Zampiron, and M. Carrara, J. Med. Chem. 45 (2002) 4931. 
5. X. Z. Wang, J. H. Yao, G. B. Jiang, J. Wang, H. L. Huang, and Y. J. Liu, Spectrochim. Acta A 133 (2014) 559.

6. H. N. Hafez, M. I. Hegab, I. S. Ahmed-Farag, and A. B. A. ElGazzar, Bioorg. Med. Chem. Lett. 18 (2008) 4538.

7. D. J. Jiang, Z. Dai, and Y. J. Li, Cardiovasc. Drug Rev. 22 (2004) 91 .

8. A. Banerjee and A. K. Mukherjee, Stain. Technol. 56 (1981) 83.

9. C. G. Knight and T. Stephens, Biochem. J. 258 (1989) 683.

10. M. Ahmad, T. A. King, D. K. Ko, B. H. Cha, and J. J. Lee, Phys. D: Appl. Phys. 35 (2002) 1473.

11. F. Shahidi and M. Naczk, Food phenolics, Technomic Pub. Co., Lancaster, 1995.

12. A. M. L. Seca, S. B. Leal, D. C. G. A. Pinto, M. C. Barreto, and A. M. S. Silva, Molecules 19 (2014) 8317.

13. M. Kondo, L. Zhang, J. Hongping, Y. Kou, and B. Ou, J. Agric. Food Chem. 57 (2009) 8788

14. A. Ilangovan, K. Anandhan, K. M. Prasad, P. Vijayakumar, R. Renganathan, D. A. Ananth, and T. Sivasudha, Med. Chem. Res. 24 (2015) 344

15. P. Iniyavan, S. Sarvaswari, and V. Vijayakumar, Res. Chem. Intermed. DOI 10.1007/s11164-014-1821-4.

16. J. Piljac-Žegarac, L. Valek, S. Martinez, and A. Belščak, Food Chem. 113 (2009) 394.

17. J. Piljac-Žegarac, L. Valek, T. Stipčević, and S. Martinez, Food Chem. 121 (2010) 820.

18. P. A. Kilmartin, Z. Honglei, and A. L. Waterhouse, Am. J. Enol. Vitic. 53 (2002) 294.

19. N. Hamdi, V. Passarelli, and A. Romerosa, C. R. Chimie 14 (2011) 548 .

20. F. Scholz and B. Meyer, in: A. J. Bard, and I. Rubinstein (Eds.), Electroanalytical Chemistry, Vol. 20, Marcel Dekker, New York, 1998, pp. 1-86.

21. A. Doménech-Carbóa, M. Martinib, L. M. de Carvalhob, C. Vi- anab, M. T. Doménech-Carbóc, and M. Silva, J. Pharm. Biomed. Anal. 80 (2013) 159.

22. Š. Komorsky-Lovrić and I. Novak, Collect. Czech. Chem. Commun. 74, (2009) 1467.

23. Š. Komorsky-Lovrić and I. Novak, J. Food Sci. 76 (2011) C916.

24. P. Schrick, K. Geick and S. R. Waldvogel, Synthesis 14 (2008) 2211.

25. D. Završnik, E. Veljović, A. Bajrović, M Vrankić, B. Gržeta, A. Osmanović, S. Špirtović-Halilović, and S. Muratović, Bulletin of Chemists and Technologists of Bosnia and Herzegovina $\mathbf{4 0}$ (2013) 15 .

26. F. Scholz, U. Schröder, and R. Gulaboski, Electrochemistry of immobilized particles and droplets, Springer, Berlin, 2005.

27. Š. Komorsky-Lovrić, N. Vukašinović, and R. Penovski, Electroanal. 15 (2003) 544.

28. Š. Komorsky-Lovrić and I. Novak, Electrochim. Acta 98 (2013) 153.

29. R. Singh, R. K. Singh, A. A. Mahdi, S. Misra, S. P. Rai, D. Singh, G. Cornélissen, and F. Halberg, In Vivo 12 (1998) 69.

30. R. J. Sinha, R. Singh, S. Mehrotra, and R. K. Singh, Indian J. Cancer 46 (2009) 146.

31. P. A. Kilmartin, Z. Honglei, and A. L. Waterhouse, J. Agric. Food Chem. 49 (2001) 1957.

32. S. Martinez, L. Valek, Ž. Petrović, M. Metikoš-Huković, and J. Piljac, J. Electroanal. Chem. 584 (2005) 92.

33. S. Chevion, E. M. Berry, N. Kitrossky, and R. Kohen, Free Radic. Biol. Med. 22 (1997) 411.

34. N. Ragubeer, D. R. Beukes, and J. L. Limson, Food Chem. 121 (2010) 227.

35. G. Le Nest, O. Caille, M. Woudstra, S. Roche, B. Burlat, V. Belle, B. Guigliarelli, and D. Lexa, Inorg. Chim. Acta 357 (2004) 2027.

36. J. Piljac, S. Martinez, T. Stipčević, Ž. Petrović, and M. MetikošHuković, Am. J. Enol. Vitic. 55 (2004) 417. 